\title{
O Pisa e o custo da repetência no Fundeb
}

João Galvão Bacchetto ${ }^{a}$

\section{Resumo}

O Brasil é um dos países com os mais altos índices de repetência segundo o relatório internacional do Pisa 2012, que mostra o alto custo desse mecanismo. Este artigo desenvolve um ensaio sobre como calcular a repetência e seu custo no Brasil. Foram utilizados os dados do Censo Escolar de 2012 e 2013 para se tentar quantificar a repetência e os valores do custo-aluno do Fundo de Manutenção e Desenvolvimento da Educação Básica e de Valorização dos Profissionais da Educação (Fundeb) para verificar seu impacto financeiro direto. O custo total da repetência permaneceu na casa de bilhões de reais, sugerindo a necessidade de se estabelecer políticas que considerem a repetência na distribuição dos recursos.

Palavras-chave: Repetência. Fundeb. Censo Escolar. Pisa.

O Brasil figurou entre os países com as maiores taxas de repetência entre os participantes do Programa Internacional de Avaliação de Estudantes (Pisa) de 2012. O total de 37,4\% dos estudantes relatou ao menos um episódio de repetência em sua vida escolar (BRASIL, 2014a). O relatório internacional do Pisa 2012 traz esse dado de repetência e explora o custo financeiro do uso desse mecanismo (OCDE, 2013). Este texto procura estimar, de forma não conclusiva, o impacto financeiro da repetência no Fundo de Manutenção e Desenvolvimento da Educação Básica e de Valorização dos Profissionais da Educação (Fundeb), com vistas a auxiliar na definição de uma metodologia de cálculo do custo e estimular a reflexão sobre o impacto financeiro da repetência.

A instituição responsável pela execução do Pisa, a Organização para a Cooperação e Desenvolvimento Econômico (OCDE), compara a distribuição dos estudantes nos diversos países participantes do Pisa 2012 e aponta que algumas nações utilizam uma estratificação vertical, na qual, devido provavelmente à repetência, alunos da mesma idade encontram-se em diferentes anos de estudos. Outra

a Instituto Nacional de Estudos e Pesquisas Educacionais Anísio Teixeira - INEP (sua opinião não representa a do órgão). Brasília, Distrito Federal, Brasil. 
estratificação seria a horizontal, na qual os estudantes são agrupados segundo modelos específicos de instrução de acordo com seus interesses ou performances. Para a OCDE, a repetência escolar teria relação com o nível socioeconômico dos estudantes, e seu efeito na aprendizagem poderia variar conforme a série/ano em que ocorre a repetência; ademais, são apontados outros estudos nos quais a repetência não beneficiaria a aprendizagem dos estudantes (OCDE, 2013).

O relatório internacional do Pisa 2012 explora também o custo da repetência; o custo direto seria o correspondente ao financiamento de mais um ano de estudo, e o custo indireto seria decorrente do atraso do ingresso desses estudantes no mundo produtivo. De maneira geral, o relatório mostra que esse processo é muito oneroso para os países; no caso brasileiro, a previsão total de custo seria de 6,7 bilhões ${ }^{1}$ de dólares americanos; caso fosse considerado apenas o custo direto da repetência, este seria de 2,2 bilhões de dólares americanos (OCDE, 2013).

O questionário contextual dos estudantes aplicado no Pisa 2012 permitiu o cálculo da incidência da repetência mediante um item com três opções de resposta. O estudante foi convidado a responder se repetiu, em algum momento, no primeiro ciclo do Ensino Fundamental, no segundo ciclo do Ensino Fundamental ou no Ensino Médio (Quadro).

Marcando "sim" em qualquer uma das alternativas, o estudante registraria ter vivenciado a repetência em seu histórico escolar. Observou-se que em muitos Estados, como Alagoas, Mato Grosso do Sul, Paraná, Pernambuco, Rio Grande do Norte, Rondônia, Roraima e Sergipe, mais de $50 \%$ da população masculina de escolas urbanas apresentaram repetência em seu histórico escolar. O estudo do Pisa revela o quanto a repetência ainda é presente na vida escolar brasileira,

Quadro. Item do Pisa 2012 sobre repetência.

\begin{tabular}{|l|c|c|c|}
\hline \multicolumn{4}{|c|}{ Você repetiu algum ano? } \\
\hline \multicolumn{3}{|c|}{ (Marque apenas uma opção em cada linha) } \\
\hline $\begin{array}{l}\text { Nos anos iniciais do Ensino Fundamental } \\
\text { (do } 1^{\circ} \text { ao } 5^{\circ} \text { ano/da } 1^{\mathrm{a}} \text { a 4 }{ }^{\mathrm{a}} \text { série) }\end{array}$ & Não, nunca & $\begin{array}{c}\text { Sim, } \\
\text { uma vez }\end{array}$ & $\begin{array}{c}\text { Sim, duas } \\
\text { vezes ou mais }\end{array}$ \\
\hline $\begin{array}{l}\text { Nos anos finais do Ensino Fundamental } \\
\text { (do 6ao } 9^{\circ} \text { ano/ da 5 }{ }^{\mathrm{a}} \text { a 8 } \text { a série) }^{\circ}\end{array}$ & $\square 1$ & $\square 2$ & $\square 3$ \\
\hline No Ensino Médio & $\square 1$ & $\square 2$ & $\square 3$ \\
\hline
\end{tabular}

Fonte: BRASIL (2013a).

${ }^{1}$ Corrigidos pelo método de poder de compra paritário - PPP (Purchasing Power Parity). 
e que, apesar dos diversos esforços realizados nas últimas décadas, ela persiste em altos patamares (BRASIL, 2014a).

Diferentemente dos cálculos de porcentagens de repetência por ano ou série, o diferencial dessa metodologia é resgatar o histórico de cada estudante segundo seu relato individual. Todavia, ela se mostra insuficiente para o cálculo do custo, pois o estudante avaliado pelo Pisa concentra-se na faixa de 15 anos de idade, e muitos ainda estarão sujeitos à repetência em seu futuro escolar. Ademais, há questionamentos sobre a forma como é realizada a amostragem do Pisa internacionalmente, o que questionaria a validade de alguns de seus resultados (KLEIN, 2011).

Na busca por um dado de melhor qualidade para quantificar a repetência no Brasil, optou-se no presente estudo por utilizar o Censo Escolar da Educação Básica produzido pelo Instituto Nacional de Estudos e Pesquisas Educacionais Anísio Teixeira (Inep), em que o código do estudante permite seu acompanhamento ao longo dos anos escolares. Por meio das matrículas informadas no Censo, aqui utilizadas para mensurar a repetência, e dos recursos financeiros disponíveis, calculam-se os valores de repasse do custo-aluno do Fundeb. A associação de cada matrícula com o custo-aluno do Fundeb, permite que, ao quantificar-se a repetência, se atribua um custo a ela.

Supõe-se que a mensuração do impacto econômico da repetência possa auxiliar na discussão de se construir, ou não, uma metodologia de distribuição de recursos que considere esse fator. Ao reter um estudante, o município (ou Estado) também está recebendo uma verba duplicada, mesmo que em anos fiscais distintos, para promover a educação daquele estudante em um mesmo ano de estudo. Independentemente de qualquer valoração sobre os fatores pedagógicos positivos ou negativos que a repetência possa ter, o que se pretende é desenhar uma possível metodologia que possa revelar a existência ou não dessa dimensionalidade financeira.

\section{Quantificando a repetência por meio do Censo Escolar}

A quantificação dos repetentes foi realizada mediante os dados do Censo Escolar da Educação Básica das edições de 2012 e 2013. Para cada estudante, há no Censo um código identificador individual que se mantém em todas as edições; há também um campo que indica seu ano/série de estudo. Quando este permaneceu igual, em 2012 e 2013, considerou-se o estudante como repetente. 
A coleta individual realizada no Censo Escolar, a partir de 2007, e a disponibilização de microdados por estudante, atualmente realizada pelo Inep, fizeram superar dificuldades de trabalho com esse instrumento. Antigamente havia dificuldade em identificar a duplicidade gerada pela circulação dos estudantes por diversas escolas (RIBEIRO, 1991).

Entretanto, foi necessário adotar alguns critérios para lidar com as bases de dados do Censo Escolar. Inicialmente, foram excluídos os registros da educação infantil e da educação de jovens e adultos, sendo consideradas apenas as matrículas do Ensino Fundamental e Médio. Os registros nos quais o campo de ano/série de ensino apresentou-se em branco também foram descartados. Outras formas organizacionais do Ensino Fundamental e Médio que pudessem ter alguma regra diferenciada de promoção ou retenção de estudantes também foram desconsideradas, excluindo-se aquelas registradas como "multi", "não seriada", "correção de fluxo", "concomitante" e "subsequente".

Assim, trabalhou-se exclusivamente com as matrículas de Ensino Fundamental regular, sistema de séries ou ano, e as de Ensino Médio regular, integrado e normal $/$ magistério. Dentro desse quantitativo, ainda foram identificadas $0,05 \%$ de matrículas duplicadas para o Censo de 2012, e 0,07\% de duplicações, em 2013. Uma das matrículas duplicadas foi excluída, sendo mantida aquela na qual o estudante se encontrava matriculado no menor ano/série; o procedimento foi adotado nos dois censos. Ao final, o universo de análise foi constituído por 38.120.738 matrículas, em 2012, e 37.417.649 matrículas, em 2013. A Tabela 1 registra o número total de matrículas iniciais no Censo, as exclusões realizadas e o universo final de matrículas utilizado neste estudo.

Depois de dar o mesmo tratamento de dados para o Censo das edições de 2012 e 2013, na sequência, procurou-se observar o fluxo dos estudantes

Tabela 1. Total de matrículas do Censo Escolar da Educação Básica de 2012 e 2013, conforme os filtros realizados.

\begin{tabular}{lcc}
\hline Variável & Censo 2012 & Censo 2013 \\
\hline Matrículas totais & 54.757 .106 & 55.424 .331 \\
$\begin{array}{l}\text { Matrículas do Ensino Fundamental e Médio regular } \\
\text { com duplicações }\end{array}$ & 38.141 .652 & 37.443 .522 \\
$\begin{array}{l}\text { Universo de matrículas do Ensino Fundamental e } \\
\text { Médio utilizado no estudo }\end{array}$ & 38.120 .738 & 37.417 .649 \\
\hline
\end{tabular}

Fonte: Elaborado pelo autor, a partir do Censo Escolar de 2012 (BRASIL, 2012a) e Censo Escolar (BRASIL, 2013b). 
entre as duas edições, considerando o ano/série de estudo e tendo como base a matrícula de 2012 .

Na Tabela 2, pode-se observar o fluxo dos estudantes entre os anos escolares de 2012 e 2013, foram construídas categorias que agrupassem os estudantes segundo o seu percurso. Foram considerados como "Promovidos" aqueles que progrediram um ou mais anos/séries entre o registro de 2012 e 2013. Estudantes da última série do Fundamental ou Médio, em 2012, e que não constavam do Censo 2013 foram considerados "Supostos Formados". A categoria "Não Localizados" diz respeito àqueles estudantes que podem ter se evadido do sistema, ou que se matricularam em outras etapas não incluídas na análise. No grupo categorizado como "Regrediu", o ano de estudo de 2013 é inferior ao registrado em 2012. No grupo de "Repetente", o único que interessa a este estudo, foram reunidos os estudantes matriculados cujos códigos de série permaneceram iguais nas edições de 2012 e 2013 do Censo Escolar da Educação Básica.

O grupo de Repetentes representou 9,6\% do total dos estudantes matriculados em 2012 e selecionados para este estudo. O cálculo da taxa de repetência constitui uma razão entre aqueles que estão refazendo o ano de estudo pelo número de matriculados originalmente naquele mesmo ano, assim, para o recorte realizado - esta seria a taxa de repetência.

Não há dados oficiais sobre repetência escolar, entendida como uma medida de fluxo que considera a matrícula repetida na mesma série em dois anos escolares subsequentes. Mas há medidas oficiais de rendimento que avaliam o resultado ao final de um único ano escolar, como a reprovação, aprovação ou abandono. Os dados de fluxo obtidos

Tabela 2. Fluxo dos estudantes matriculados em 2012 em relação às matrículas observadas em 2013.

\begin{tabular}{lcc}
\hline Fluxo do estudante & Número de estudantes & $\%$ \\
\hline Promovido & 28.398 .545 & 74,5 \\
Promovido mais de um ano/série & 305.099 & 0,8 \\
Repetente & 3.653 .730 & 9,6 \\
Regrediu de ano/série & 91.989 & 0,2 \\
Não localizado & 3.097 .132 & 8,1 \\
Suposto Formado Ensino Médio & 2.132 .401 & 5,6 \\
Suposto Formado Ensino Fundamental & 441.842 & 1,2 \\
Total & 38.120 .738 & 100,0 \\
\hline
\end{tabular}

Fonte: Elaborado pelo autor, a partir do Censo Escolar de 2012 (BRASIL, 2012a) e Censo Escolar (BRASIL, 2013b). 
não são radicalmente discrepantes em relação aos dados de rendimento divulgados oficialmente pelo Inep, que apontam 9,1\% de reprovação no Ensino Fundamental e 12,2\% de reprovação no Ensino Médio (BRASIL, 2012b) (Tabela 3).

O presente estudo atém-se à questão do custo da repetência, de modo que se restringe aos aspectos implicados diretamente no repasse do Fundeb, quais sejam: nível e etapa de ensino oferecido, localização urbana/rural, Unidade Federativa, ser estudante com deficiência e a dependência administrativa (Tabela 4).

A rede federal, embora tenha apresentado a maior taxa de repetência, possuía apenas $0,4 \%$ das matrículas nacionais em 2012; a rede particular, por sua vez, respondeu por $14,2 \%$ das matrículas e apresentou a menor taxa de repetência. Uma vez que ambas as redes não são financiadas diretamente pelo Fundeb, fugindo ao escopo deste trabalho, os dados de repetência a elas relacionados não serão computados no cálculo do custo repetência.

Considerando apenas as redes estaduais e municipais, buscou-se quantificar a repetência em cada uma das unidades federativas e desagregá-las por nível e etapa de ensino, isso foi feito na Tabela 5.

Tabela 3. Matrículas, repetência e taxa de repetência em 2012 segundo os níveis de ensino.

\begin{tabular}{lccc}
\hline Variável & Matrículas & Repetentes & $\begin{array}{c}\text { Taxa de } \\
\text { repetência (\%) }\end{array}$ \\
\hline Nível Fundamental - anos iniciais & 16.126 .358 & 1.314 .017 & 8,1 \\
Nível Fundamental - anos finais & 13.685 .154 & 1.474 .075 & 10,8 \\
Nível Médio & 8.309 .226 & 865.638 & 10,4 \\
\hline
\end{tabular}

Fonte: Elaborado pelo autor, a partir do Censo Escolar de 2012 (BRASIL, 2012a) e Censo Escolar (BRASIL, 2013b).

Tabela 4. Matrículas, repetência, taxa de repetência segundo dependência administrativa.

\begin{tabular}{lccc}
\hline Variável & Matrículas & Repetentes & Taxa (\%) \\
\hline Federal & 141.237 & 17.011 & 12,0 \\
Estadual & 16.158 .672 & 1.642 .625 & 10,2 \\
Municipal & 16.412 .520 & 1.753 .871 & 10,7 \\
Particular & 5.408 .309 & 240.223 & 4,4 \\
Total & 38.120 .738 & 3.653 .730 & 9,6 \\
\hline
\end{tabular}

Fonte: Elaborado pelo autor, a partir do Censo Escolar de 2012 (BRASIL, 2012a) e Censo Escolar (BRASIL, 2013b). 
Os Estados de São Paulo, Rio de Janeiro, Bahia e Minas Gerais concentraram maior número de repetentes, provavelmente devido a sua maior população. Para se evitar um julgamento parcial sobre as políticas educacionais locais, convém

Tabela 5. Total de registros classificados como repetência por rede municipal e estadual, etapa e nível de ensino, segundo unidades federativas.

\begin{tabular}{|c|c|c|c|c|c|c|}
\hline \multirow[b]{2}{*}{ UF } & \multicolumn{3}{|c|}{ Rede Estadual } & \multicolumn{3}{|c|}{ Rede Municipal } \\
\hline & $\begin{array}{c}\text { Ensino } \\
\text { Fundamental } \\
\text { - anos iniciais }\end{array}$ & $\begin{array}{c}\text { Ensino } \\
\text { Fundamental } \\
\text { - anos finais }\end{array}$ & $\begin{array}{l}\text { Ensino } \\
\text { Médio }\end{array}$ & $\begin{array}{c}\text { Ensino } \\
\text { Fundamental } \\
\text { - anos iniciais }\end{array}$ & $\begin{array}{c}\text { Ensino } \\
\text { Fundamental } \\
\text { - anos finais }\end{array}$ & $\begin{array}{l}\text { Ensino } \\
\text { Médio }\end{array}$ \\
\hline$A C$ & 4.635 & 3.457 & 4.759 & 6.670 & 1.120 & - \\
\hline $\mathrm{AL}$ & 3.137 & 15.494 & 14.917 & 37.778 & 37.427 & 30 \\
\hline AM & 5.716 & 16.430 & 13.633 & 45.758 & 15.278 & - \\
\hline AP & 4.829 & 6.872 & 5.320 & 3.622 & 473 & - \\
\hline BA & 2.421 & 51.626 & 64.359 & 157.510 & 109.333 & 943 \\
\hline CE & 568 & 6.448 & 22.895 & 44.128 & 40.310 & 5 \\
\hline DF & 16.657 & 24.833 & 14.219 & - & - & - \\
\hline ES & 2.852 & 11.114 & 16.989 & 18.256 & 22.003 & 4 \\
\hline GO & 1.199 & 16.116 & 18.926 & 26.320 & 11.097 & 47 \\
\hline MA & 4.299 & 9.710 & 32.277 & 65.583 & 54.738 & 612 \\
\hline MG & 7.188 & 86.094 & 74.821 & 44.999 & 41.602 & 790 \\
\hline MS & 8.179 & 16.641 & 12.456 & 18.028 & 10.339 & 9 \\
\hline MT & 863 & 2.202 & 26.865 & 6.994 & 3.997 & 8 \\
\hline PA & 10.961 & 23.822 & 39.865 & 101.880 & 48.471 & 22 \\
\hline PB & 7.481 & 18.537 & 12.441 & 28.926 & 21.521 & 195 \\
\hline PE & 4.376 & 32.562 & 27.714 & 72.896 & 45.993 & 304 \\
\hline PI & 4.075 & 8.498 & 15.403 & 36.256 & 22.190 & 95 \\
\hline PR & 655 & 83.187 & 53.535 & 48.713 & 2167 & - \\
\hline RJ & 2.839 & 35.035 & 47.102 & 106.538 & 64.565 & 749 \\
\hline RN & 7.857 & 14.818 & 16.038 & 26.849 & 21.271 & 3 \\
\hline RO & 5.282 & 13.843 & 6.357 & 9.692 & 5.391 & 7 \\
\hline RR & 1.230 & 5.003 & 2.864 & 2.212 & 253 & - \\
\hline RS & 18.875 & 53.313 & 45.539 & 31.117 & 42.114 & 884 \\
\hline SC & 5.724 & 12.773 & 20.395 & 12.285 & 12.771 & 59 \\
\hline SE & 4.165 & 13.045 & 8.588 & 22.811 & 17.517 & 5 \\
\hline SP & 15.599 & 98.942 & 170.638 & 72.247 & 37.697 & 2.285 \\
\hline TO & 3.913 & 10.644 & 7.076 & 5.896 & 3.199 & 14 \\
\hline
\end{tabular}

Fonte: Elaborado pelo autor, a partir do Censo Escolar de 2012 (BRASIL, 2012a) e Censo Escolar (BRASIL, 2013b). 
observar as taxas de repetência, que consideram o total de matriculados e podem oferecer dados mais qualificados do que considerar isoladamente o número de repetentes. Isso pode ser observado na Tabela 6 .

Ao se ponderar os dados pela quantidade de estudantes matriculados, a rede paulista apresenta-se com uma das menores taxas de repetência no Ensino Fundamental, ao lado de Estados como Santa Catarina, Goiás, Mato Grosso e Amazonas. No outro

Tabela 6. Taxas de repetência por rede municipal e estadual, etapa e nível de ensino, segundo unidades federativas.

\begin{tabular}{|c|c|c|c|c|c|c|}
\hline \multirow[b]{2}{*}{ UF } & \multicolumn{3}{|c|}{ Rede Estadual } & \multicolumn{3}{|c|}{ Rede Municipal } \\
\hline & $\begin{array}{c}\text { Ensino } \\
\text { Fundamental - } \\
\text { anos iniciais (\%) }\end{array}$ & $\begin{array}{c}\text { Ensino } \\
\text { Fundamental - } \\
\text { anos finais (\%) }\end{array}$ & $\begin{array}{l}\text { Ensino } \\
\text { Médio } \\
\text { (\%) }\end{array}$ & $\begin{array}{l}\text { Ensino } \\
\text { Fundamental - } \\
\text { anos iniciais (\%) }\end{array}$ & $\begin{array}{c}\text { Ensino } \\
\text { Fundamental - } \\
\text { anos finais (\%) }\end{array}$ & $\begin{array}{c}\text { Ensino } \\
\text { Médio } \\
(\%)\end{array}$ \\
\hline AC & 10,5 & 6,5 & 13,0 & 13,6 & 10,4 & - \\
\hline $\mathrm{AL}$ & 17,3 & 22,1 & 13,9 & 15,0 & 21,8 & 4,5 \\
\hline AM & 5,7 & 9,3 & 8,2 & 15,1 & 12,4 & - \\
\hline AP & 13,0 & 12,8 & 15,1 & 9,5 & 11,2 & - \\
\hline BA & 13,9 & 17,2 & 12,4 & 14,6 & 17,2 & 9,5 \\
\hline CE & 10,9 & 9,4 & 6,4 & 7,5 & 8,9 & 5,4 \\
\hline DF & 10,1 & 17,6 & 17,5 & - & - & - \\
\hline ES & 6,5 & 14,3 & 15,0 & 8,7 & 16,3 & 3,2 \\
\hline GO & 3,5 & 7,1 & 8,7 & 7,1 & 9,4 & 8,8 \\
\hline MA & 13,2 & 10,7 & 11,9 & 10,5 & 12,3 & 8,6 \\
\hline MG & 1,6 & 10,2 & 10,2 & 5,2 & 11,0 & 9,6 \\
\hline MS & 13,6 & 19,3 & 14,3 & 11,9 & 13,4 & 7,1 \\
\hline MT & 1,1 & 1,7 & 19,2 & 4,5 & 6,1 & 10,1 \\
\hline PA & 13,7 & 14,8 & 12,5 & 13,4 & 12,2 & 11,8 \\
\hline PB & 12,4 & 17,8 & 10,9 & 13,1 & 16,1 & 7,1 \\
\hline $\mathrm{PE}$ & 12,6 & 12,2 & 8,4 & 12,8 & 16,4 & 9,1 \\
\hline PI & 14,6 & 14,1 & 11,7 & 14,9 & 14,5 & 8,2 \\
\hline$P R$ & 12,7 & 12,9 & 12,9 & 7,0 & 12,9 & - \\
\hline RJ & 10,0 & 12,3 & 10,9 & 12,7 & 13,5 & 12,6 \\
\hline RN & 15,5 & 19,7 & 13,6 & 14,6 & 19,9 & 9,1 \\
\hline RO & 10,1 & 16,7 & 11,4 & 10,2 & 15,0 & 5,4 \\
\hline $\mathrm{RR}$ & 7,8 & 13,5 & 15,4 & 6,9 & 14,4 & - \\
\hline RS & 6,2 & 17,2 & 13,7 & 7,5 & 14,9 & 17,2 \\
\hline SC & 4,3 & 6,7 & 9,7 & 4,5 & 8,0 & 4,7 \\
\hline SE & 11,1 & 21,2 & 13,1 & 18,1 & 23,4 & 3,0 \\
\hline SP & 2,3 & 5,5 & 10,7 & 4,2 & 6,0 & 9,7 \\
\hline TO & 8,4 & 13,2 & 11,1 & 7,1 & 10,4 & 14,0 \\
\hline
\end{tabular}

Fonte: Elaborado pelo autor, a partir do Censo Escolar de 2012 (BRASIL, 2012a) e Censo Escolar (BRASIL, 2013b). 
extremo encontram-se Estados com altas taxas de repetência, como Alagoas, Sergipe, Rio Grande do Norte, Bahia, Mato Grosso do Sul, Pará, Piauí e Distrito Federal.

Há, também, uma semelhança das taxas de repetência das redes estaduais e municipais no interior de um mesmo Estado. Isso é mais visível em São Paulo, Mato Grosso e Ceará, onde as duas redes possuem taxas mais reduzidas, ou na Bahia, Alagoas e Sergipe, onde ambas as redes apresentam altas taxas. Todavia, para o cálculo do custo da repetência é necessário, ainda, que se estudem dois elementos: a localização da escola e a presença de estudantes com deficiência.

Aárea urbana concentrou $87,7 \%$ das matrículas e apresentou uma taxa de repetência de 9,3\%; na área rural, a taxa de repetência foi de $11,9 \%$, o que representa mais de meio milhão de estudantes brasileiros (Tabela 7).

O grupo de estudantes com deficiência, por sua vez, mostrou uma das mais altas taxas de repetência dentre todos os recortes nacionais analisados, com 21,8\% dos matriculados em 2012 (Tabela 8).

Entende-se aqui que a discussão sobre a repetência do estudante com deficiência merece ser realizada dentro de um contexto mais amplo com especialistas da área; abordando aspectos como recursos especiais presentes nas escolas, ou dificuldades particulares de um ou outro grupo. Assim, este

Tabela 7. Matrícula, Repetência e Taxa de repetência segundo área de localização da escola.

\begin{tabular}{lccc}
\hline Variável & Matrículas & Repetentes & Taxa (\%) \\
\hline Urbana & 33.416 .285 & 3.091 .829 & 9,3 \\
Rural & 4.704 .453 & 561.901 & 11,9 \\
Total & 38.120 .738 & 3.653 .730 & 9,6 \\
\hline
\end{tabular}

Fonte: Elaborado pelo autor, a partir do Censo Escolar de 2012 (BRASIL, 2012a) e Censo Escolar (BRASIL, 2013b).

Tabela 8. Matrícula, Repetência e Taxa de repetência segundo deficiência.

\begin{tabular}{lccc}
\hline Variável & Matrículas & Repetentes & Taxa (\%) \\
\hline Estudantes sem deficiência & 37.468 .362 & 3.511 .455 & 9,4 \\
Estudantes com deficiência & 652.376 & 142.275 & 21,8 \\
\hline
\end{tabular}

Fonte: Elaborado pelo autor, a partir do Censo Escolar de 2012 (BRASIL, 2012a) e Censo Escolar (BRASIL, 2013b). 
quantitativo não será considerado no cálculo do custo repetência, mesmo porque eles possuem um valor diferenciado no repasse do Fundeb. De toda forma, registra-se a alta taxa de repetência, que deve ser tema para outros estudos mais aprofundados.

A Tabela 9 sintetiza os números da repetência, que serão utilizados para o cálculo do custo, onde não constam as redes privada, federal e os estudantes com deficiência. Os dados são apresentados conforme os aspectos considerados relevantes para análise, ou seja, por área urbana ou rural, por etapa e nível de ensino, e segundo as unidades da federação; fatores que são definidores do preço por aluno repassado pelo Fundeb (Brasil, 2012c). Com isso, totalizou-se 3.290 .949 de repetentes no ano de 2012 , sendo $75,7 \%$ destes localizados no Ensino Fundamental.

\section{O custo da repetência}

Para estimar o custo da repetência no presente estudo serão utilizados como referência os valores por aluno do Fundeb. Este fundo, resumidamente, é assim definido:

É um fundo especial, de natureza contábil e de âmbito estadual (um fundo por Estado e Distrito Federal, num total de vinte e sete fundos), formado, na quase totalidade, por recursos provenientes dos impostos e transferências dos Estados, Distrito Federal e municípios, vinculados à educação por força do disposto no art. 212 da Constituição Federal. Além desses recursos, ainda compõe o Fundeb, a título de complementação, uma parcela de recursos federais, sempre que, no âmbito de cada Estado, seu valor por aluno não alcançar o mínimo definido nacionalmente. Independentemente da origem, todo o recurso gerado é redistribuído para aplicação exclusiva na educação básica. [...] A distribuição é realizada com base no número de alunos da educação básica pública, de acordo com dados do último censo escolar, sendo computados os alunos matriculados nos respectivos âmbitos de atuação prioritária, conforme art. 211 da Constituição Federal (BRASIL, 2014b).

O custo aluno do Fundeb apresenta critérios de variação, sendo aqui restritos ao ensino regular nos níveis fundamental e médio, neste último ainda foram considerados aqueles registrados como "integrado" e "normal/Magistério". Optou-se por utilizar os valores de 2012 (EVASÃO e repetência...., 2012), ano em que a repetência foi mapeada, assim, sabe-se que o ente federado recebeu uma determinada quantia em 
dinheiro para a escolarização daquele estudante repetente. Os valores anuais por aluno do Fundeb, em 2012, foram definidos na Portaria Interministerial $\mathrm{n}^{\circ} 1.809$, de 28 dezembro de 2011 (BRASIL, 2011), e estão expressos na Tabela 10.

Tabela 9. Total de registros classificados como repetência por localização urbana rural, nível e etapa de ensino, segundo unidades federativas.

\begin{tabular}{|c|c|c|c|c|c|c|c|}
\hline \multirow[b]{2}{*}{ UF } & \multicolumn{3}{|c|}{ Localização Urbana } & \multicolumn{3}{|c|}{ Localização Rural } & \multirow[b]{2}{*}{ Total } \\
\hline & $\begin{array}{c}\text { Ensino } \\
\text { Fundamental } \\
\text { - anos iniciais }\end{array}$ & $\begin{array}{c}\text { Ensino } \\
\text { Fundamental } \\
\text { - anos finais }\end{array}$ & $\begin{array}{l}\text { Ensino } \\
\text { Médio }\end{array}$ & $\begin{array}{c}\text { Ensino } \\
\text { Fundamental } \\
\text { - anos iniciais }\end{array}$ & $\begin{array}{c}\text { Ensino } \\
\text { Fundamental } \\
\text { - anos finais }\end{array}$ & $\begin{array}{l}\text { Ensino } \\
\text { Médio }\end{array}$ & \\
\hline$A C$ & 4.449 & 3.027 & 4.376 & 6.299 & 1.426 & 338 & 19.915 \\
\hline $\mathrm{AL}$ & 23.631 & 44.045 & 14.325 & 14.909 & 8.155 & 577 & 105.642 \\
\hline AM & 29.679 & 25.446 & 12.384 & 20.439 & 6.093 & 1.237 & 95.278 \\
\hline AP & 5.287 & 5.879 & 4.839 & 2.689 & 1.353 & 456 & 20.503 \\
\hline BA & 89.119 & 124.093 & 63.129 & 63.378 & 34.921 & 1.981 & 376.621 \\
\hline CE & 30.482 & 36.557 & 22.282 & 11.902 & 9.434 & 539 & 111.196 \\
\hline DF & 13.628 & 23.313 & 13.844 & 922 & 1.096 & 217 & 53.020 \\
\hline ES & 16.818 & 30.729 & 16.696 & 3.011 & 1.850 & 213 & 69.317 \\
\hline GO & 23.746 & 25.391 & 18.708 & 1.962 & 1.166 & 130 & 71.103 \\
\hline MA & 32.114 & 39.716 & 28.294 & 35.396 & 23.875 & 4.427 & 163.822 \\
\hline MG & 39.552 & 119.088 & 74.672 & 7.647 & 6.509 & 684 & 248.152 \\
\hline MS & 19.705 & 24.019 & 11.811 & 4.502 & 2.523 & 569 & 63.129 \\
\hline MT & 5.825 & 4.690 & 25.397 & 1.558 & 1.394 & 1.444 & 40.308 \\
\hline PA & 54.813 & 53.138 & 36.412 & 53.949 & 18.472 & 3.311 & 220.095 \\
\hline PB & 23.025 & 35.788 & 12.352 & 11.301 & 3.777 & 199 & 86.442 \\
\hline PE & 47.153 & 66.724 & 26.444 & 25.732 & 11.170 & 1.489 & 178.712 \\
\hline PI & 21.497 & 22.893 & 14.714 & 17.139 & 7.482 & 733 & 84.458 \\
\hline$P R$ & 38.454 & 79.358 & 51.971 & 4.511 & 3.276 & 1.120 & 178.690 \\
\hline RJ & 87.017 & 93.720 & 46.782 & 11.633 & 5.067 & 714 & 244.933 \\
\hline RN & 23.070 & 30.893 & 15.701 & 9.818 & 4.521 & 234 & 84.237 \\
\hline RO & 9.250 & 15.292 & 6.082 & 4.776 & 3.658 & 254 & 39.312 \\
\hline RR & 2.033 & 4.104 & 2.589 & 1.335 & 1.098 & 262 & 11.421 \\
\hline RS & 38.432 & 85.077 & 45.102 & 5.381 & 8.173 & 976 & 183.141 \\
\hline SC & 15.493 & 23.659 & 19.995 & 1.920 & 1.471 & 350 & 62.888 \\
\hline SE & 14.963 & 23.750 & 8.281 & 11.143 & 6.596 & 284 & 65.017 \\
\hline SP & 76.903 & 131.382 & 170.434 & 3.111 & 1.662 & 1.305 & 384.797 \\
\hline TO & 5.978 & 11.681 & 6.800 & 2.366 & 1.727 & 248 & 28.800 \\
\hline Total & 792.116 & 1.183 .452 & 774.416 & 338.729 & 177.945 & 24.291 & 3.290 .949 \\
\hline
\end{tabular}

Fonte: Elaborado pelo autor, a partir do Censo Escolar de 2012 (BRASIL, 2012a) e Censo Escolar (BRASIL, 2013b). 
Nos valores consolidados do Fundeb 2012, foram consideradas 42.729 .758 matrículas e um repasse de $\mathrm{R} \$ 96,2$ bilhões. No caso deste estudo, é importante realçar que foram feitas diversas exclusões como as matrículas da Educação Infantil, da Educação de Jovens e Adultos, de estudantes com deficiência, e das matrículas em escolas particulares e federais.

Tabela 10. Valor anual em reais do aluno distribuído pelo Fundeb no exercício de 2012, por localização urbana ou rural, nível e etapa de ensino, segundo unidades federativas.

\begin{tabular}{|c|c|c|c|c|c|c|}
\hline \multirow[b]{2}{*}{ UF } & \multicolumn{3}{|c|}{ Localização Urbana } & \multicolumn{3}{|c|}{ Localização Rural } \\
\hline & $\begin{array}{c}\text { Ensino } \\
\text { Fundamental } \\
\text { - anos iniciais }\end{array}$ & $\begin{array}{c}\text { Ensino } \\
\text { Fundamental } \\
\text { - anos finais }\end{array}$ & $\begin{array}{l}\text { Ensino } \\
\text { Médio }\end{array}$ & $\begin{array}{c}\text { Ensino } \\
\text { Fundamental } \\
\text { - anos iniciais }\end{array}$ & $\begin{array}{c}\text { Ensino } \\
\text { Fundamental } \\
\text { - anos finais }\end{array}$ & $\begin{array}{l}\text { Ensino } \\
\text { Médio }\end{array}$ \\
\hline$A C$ & $2.626,36$ & $2.888,99$ & $3.151,63$ & $3.020,31$ & $3.151,63$ & $3.414,26$ \\
\hline $\mathrm{AL}$ & $2.096,68$ & $2.306,35$ & $2.516,02$ & $2.411,19$ & $2.516,02$ & $2.725,69$ \\
\hline AM & $2.096,68$ & $2.306,35$ & $2.516,02$ & $2.411,19$ & $2.516,02$ & $2.725,69$ \\
\hline AP & $2.871,54$ & $3.158,69$ & $3.445,85$ & $3.302,27$ & $3.445,85$ & $3.733,00$ \\
\hline BA & $2.096,68$ & $2.306,35$ & $2.516,02$ & 2411,19 & $2.516,02$ & $2.725,69$ \\
\hline CE & $2.096,68$ & $2.306,35$ & $2.516,02$ & $2.411,19$ & $2.516,02$ & $2.725,69$ \\
\hline DF & $2.670,70$ & $2.937,77$ & $3.204,84$ & $3.071,30$ & $3.204,84$ & $3.471,91$ \\
\hline ES & $2.831,67$ & $3.114,84$ & $3.398,00$ & $3.256,42$ & $3.398,00$ & $3.681,17$ \\
\hline GO & $2.534,87$ & $2.788,35$ & $3.041,84$ & $2.915,10$ & $3.041,84$ & $3.295,33$ \\
\hline MA & $2.096,68$ & $2.306,35$ & $2.516,02$ & $2.411,19$ & $2.516,02$ & $2.725,69$ \\
\hline MG & $2.288,64$ & $2.517,50$ & $2.746,37$ & $2.631,94$ & $2.746,37$ & $2.975,23$ \\
\hline MS & $2.477,02$ & $2.724,72$ & $2.972,42$ & $2.848,57$ & $2.972,42$ & $3.220,12$ \\
\hline MT & $2.121,10$ & $2.333,21$ & $2.545,32$ & $2.439,26$ & $2.545,32$ & $2.757,43$ \\
\hline PA & $2.096,68$ & $2.306,35$ & $2.516,02$ & $2.411,19$ & $2.516,02$ & $2.725,69$ \\
\hline PB & $2.096,68$ & $2.306,35$ & $2.516,02$ & $2.411,19$ & $2.516,02$ & $2.725,69$ \\
\hline PE & $2.096,68$ & $2.306,35$ & $2.516,02$ & $2.411,19$ & $2.516,02$ & $2.725,69$ \\
\hline PI & $2.096,68$ & $2.306,35$ & $2.516,02$ & $2.411,19$ & $2.516,02$ & $2.725,69$ \\
\hline$P R$ & $2.226,51$ & $2.449,16$ & $2.671,81$ & $2.560,49$ & $2.671,81$ & $2.894,46$ \\
\hline RJ & $2.483,25$ & $2.731,57$ & $2.979,90$ & $2.855,73$ & $2.979,90$ & $3.228,22$ \\
\hline RN & $2.106,34$ & $2.316,98$ & $2.527,61$ & $2.422,30$ & $2.527,61$ & $2.738,25$ \\
\hline RO & $2.428,84$ & $2.671,73$ & $2.914,61$ & $2.793,17$ & $2.914,61$ & $3.157,49$ \\
\hline $\mathrm{RR}$ & $3.531,27$ & $3.884,39$ & $4.237,52$ & $4.060,96$ & $4.237,52$ & $4.590,65$ \\
\hline RS & $2.913,05$ & $3.204,36$ & $3.495,67$ & $3.350,01$ & $3.495,67$ & $3.786,97$ \\
\hline SC & $2.609,79$ & $2.870,77$ & $3.131,75$ & $3.001,26$ & $3.131,75$ & $3.392,73$ \\
\hline SE & $2.447,12$ & $2.691,83$ & $2.936,55$ & $2.814,19$ & $2.936,55$ & $3.181,26$ \\
\hline SP & $3.192,81$ & $3.512,09$ & $3.831,37$ & $3.671,73$ & $3.831,37$ & $4.150,65$ \\
\hline TO & $2.671,98$ & $2.939,18$ & $3.206,38$ & $3.072,78$ & $3.206,38$ & $3.473,58$ \\
\hline
\end{tabular}

Fonte: Fundo Nacional de Desenvolvimento da Educação (BRASIL, 2014c). 
A partir dos dados de repetência apresentados na Tabela 9 e repasse de recursos do Fundeb por aluno, na Tabela 10, ambos considerando as mesmas desagregações, buscou-se estimar o custo da repetência. $\mathrm{O}$ cálculo realizado multiplicou o número de repetentes de cada um dos segmentos mapeados pelo seu valor Fundeb. $\mathrm{O}$ resultado encontrado, em milhões de reais, pode ser verificado na Tabela 11.

O mais alto custo de repetência ficou associado à área urbana, com 7,38 bilhões de reais, enquanto a área rural apresentou 1,41 bilhão de reais. Esses valores são esperados devido à maior concentração populacional em áreas urbanas. Entretanto, como o valor do repasse do Fundeb da área rural é superior ao da área urbana, proporcionalmente a repetência da área rural é mais cara. Observou-se apenas que os anos iniciais rurais no Acre, Maranhão e Pará, possuem um custo superior ao das respectivas áreas urbanas.

Ao se analisar o nível e etapa de ensino, observa-se que os anos finais do Ensino Fundamental registraram 3,63 bilhões de reais, seguido pelos anos iniciais com 2,75 bilhões de reais, e pelo Ensino Médio com 2,41 bilhões de reais. No Amazonas, Amapá, Maranhão, Pará e Piauí, observou-se que o custo da repetência é superior nos anos iniciais, e decresce nos anos finais e, novamente, no Ensino Médio, quando são agregadas as áreas urbanas e rurais. Em São Paulo, observa-se o oposto: o custo cresce conforme mais alto é o nível de ensino.

O Estado de São Paulo, seguido por Bahia e Rio de Janeiro, foram aqueles que apresentaram os maiores valores do custo associado à repetência. Por sua vez, Minas Gerais, que possui mais municípios e é mais populoso que o Rio de Janeiro, por exemplo, ficou com a quarta colocação em termos do total de custo.

O valor estimado de $\mathrm{R} \$ 8,8$ bilhões repassados para a matrícula de alunos que repetiram representa $9,1 \%$ do total do Fundeb, em 2012. Esse não é um valor final para o Brasil, pois a esses valores serão adicionados os complementos dos Estados e municípios que são praticamente impossíveis de serem computados, devido à grande quantidade de orçamentos municipais. Assim, pode-se apenas afirmar que esta é uma estimativa do custo direto da repetência baseada nos valores do Fundeb para 2012.

Como mencionado, a OCDE ainda considera custos indiretos como a tardia inserção no mercado de trabalho do jovem que repetiu ou, em alguns casos, a inserção precoce sem a devida formação completa. Martin West (2014) estima que o custo direto da repetência nos Estados Unidos possa superar 12 bilhões de dólares americanos, mostrando que essa política é bastante cara também em outros países. 
Tabela 11. Valores da repetência em 2012 em milhões de reais por localização urbana e rural, nível e etapa de ensino, segundo unidades federativas.

\begin{tabular}{|c|c|c|c|c|c|c|c|}
\hline \multirow[b]{2}{*}{ UF } & \multicolumn{3}{|c|}{ Urbana } & \multicolumn{3}{|c|}{ Rural } & \multirow[b]{2}{*}{ Total } \\
\hline & $\begin{array}{c}\text { Ensino } \\
\text { Fundamental } \\
\text { - anos iniciais }\end{array}$ & $\begin{array}{c}\text { Ensino } \\
\text { Fundamental } \\
\text { - anos finais }\end{array}$ & $\begin{array}{l}\text { Ensino } \\
\text { Médio }\end{array}$ & $\begin{array}{c}\text { Ensino } \\
\text { Fundamental } \\
\text { - anos iniciais }\end{array}$ & $\begin{array}{c}\text { Ensino } \\
\text { Fundamental } \\
\text { - anos finais }\end{array}$ & $\begin{array}{l}\text { Ensino } \\
\text { Médio }\end{array}$ & \\
\hline$A C$ & 11,7 & 8,7 & 13,8 & 19,0 & 4,5 & 1,2 & 58,9 \\
\hline $\mathrm{AL}$ & 49,5 & 101,6 & 36,0 & 35,9 & 20,5 & 1,6 & 245,2 \\
\hline AM & 62,2 & 58,7 & 31,2 & 49,3 & 15,3 & 3,4 & 220,1 \\
\hline $\mathrm{AP}$ & 15,2 & 18,6 & 16,7 & 8,9 & 4,7 & 1,7 & 65,7 \\
\hline BA & 186,9 & 286,2 & 158,8 & 152,8 & 87,9 & 5,4 & 878,0 \\
\hline CE & 63,9 & 84,3 & 56,1 & 28,7 & 23,7 & 1,5 & 258,2 \\
\hline DF & 36,4 & 68,5 & 44,4 & 2,8 & 3,5 & 0,8 & 156,3 \\
\hline ES & 47,6 & 95,7 & 56,7 & 9,8 & 6,3 & 0,8 & 216,9 \\
\hline GO & 60,2 & 70,8 & 56,9 & 5,7 & 3,5 & 0,4 & 197,6 \\
\hline MA & 67,3 & 91,6 & 71,2 & 85,3 & 60,1 & 12,1 & 387,6 \\
\hline MG & 90,5 & 299,8 & 205,1 & 20,1 & 17,9 & 2,0 & 635,4 \\
\hline MS & 48,8 & 65,4 & 35,1 & 12,8 & 7,5 & 1,8 & 171,5 \\
\hline MT & 12,4 & 10,9 & 64,6 & 3,8 & 3,5 & 4,0 & 99,3 \\
\hline PA & 114,9 & 122,6 & 91,6 & 130,1 & 46,5 & 9,0 & 514,7 \\
\hline PB & 48,3 & 82,5 & 31,1 & 27,2 & 9,5 & 0,5 & 199,2 \\
\hline PE & 98,9 & 153,9 & 66,5 & 62,0 & 28,1 & 4,1 & 413,5 \\
\hline PI & 45,1 & 52,8 & 37,0 & 41,3 & 18,8 & 2,0 & 197,0 \\
\hline$P R$ & 85,6 & 194,4 & 138,9 & 11,6 & 8,8 & 3,2 & 442,4 \\
\hline RJ & 216,1 & 256,0 & 139,4 & 33,2 & 15,1 & 2,3 & 662,1 \\
\hline $\mathrm{RN}$ & 48,6 & 71,6 & 39,7 & 23,8 & 11,4 & 0,6 & 195,7 \\
\hline RO & 22,5 & 40,9 & 17,7 & 13,3 & 10,7 & 0,8 & 105,9 \\
\hline $\mathrm{RR}$ & 7,2 & 15,9 & 11,0 & 5,4 & 4,7 & 1,2 & 45,4 \\
\hline RS & 112,0 & 272,6 & 157,7 & 18,0 & 28,6 & 3,7 & 592,5 \\
\hline SC & 40,4 & 67,9 & 62,6 & 5,8 & 4,6 & 1,2 & 182,5 \\
\hline SE & 36,6 & 63,9 & 24,3 & 31,4 & 19,4 & 0,9 & 176,5 \\
\hline SP & 245,5 & 461,4 & 653,0 & 11,4 & 6,4 & 5,4 & $1.383,2$ \\
\hline TO & 16,0 & 34,3 & 21,8 & 7,3 & 5,5 & 0,9 & 85,8 \\
\hline Brasil & $1.890,2$ & $3.151,6$ & $2.338,9$ & 857,0 & 476,9 & 72,4 & $8.787,0$ \\
\hline
\end{tabular}

Fonte: Autor (2014).

A revista Nova Escola (REPETÊNCIA..., 2014), mencionando estudo de 2007 da UNESCO, publicou um custo de 10 bilhões de reais por ano, o que é relativamente superior ao encontrado neste ensaio. O Correio Braziliense estimou que o custo 
da repetência e da evasão seria próximo a 4,8 bilhões de reais, somente para o Ensino Médio, em 2012, o que é bem superior ao encontrado neste estudo, que não considerou os dados de evasão; aqui, a repetência do Ensino Médio ficou em 2,6 bilhões de reais. Com esses dados em mãos, é possível realizar uma discussão pontual sobre as implicações da repetência no financiamento da educação, mais particularmente no Fundeb.

\section{Alguns apontamentos}

Aquantidade de estudantes que repetem e os custos associados a essa prática pedagógica não são irrisórios para a realidade educacional brasileira. Um ponto a ser destacado é que não há muitos estudos sobre a eficácia do mecanismo da repetência, como visto anteriormente, a OCDE também aponta a associação da repetência com o nível socioeconômico do estudante. Alves, Ortigão e Franco (2007) mostram que a repetência incide diferentemente em diversos grupos sociais de acordo com características, tais como o gênero, a etnia e o nível socioeconômico. Nesta perspectiva, entende-se que a repetência consiste em um mecanismo que não necessariamente atua somente por motivação pedagógica, supostamente baseada na aprendizagem dos estudantes, mas que reflete as desigualdades sociais brasileiras e de acesso à educação de qualidade.

Há de se ressalvar que a repetência pode assumir aspectos positivos, por exemplo, quando ocorre, por razões de trabalho ou saúde; nesses casos, ela permite ao estudante concluir o curso num outro ano. Diante de algo que atinge a uma boa parcela do alunado, nota-se a falta de registros sobre a motivação da repetência, se decorrente de um abandono escolar (o que seria bastante difícil com a vigência do Estatuto da Criança e do Adolescente) com rematrícula no ano seguinte, ou se o aluno frequentou as aulas por todo o ano e foi reprovado por motivos pedagógicos. Para avançar nesta discussão, seria importante qualificar esta motivação, criando esse registro nas escolas, secretarias estaduais e municipais de educação.

Revela-se legítimo, inclusive, questionar se a repetência produz o efeito pedagógico desejado. Riani, Silva e Soares (2012) mostram que os estudantes repetentes, em média, apresentam resultados em testes piores do que seus pares não repetentes, o que questiona a eficácia pedagógica deste mecanismo. Internacionalmente, a OCDE (2013) também cita outros estudos que questionariam a eficácia da repetência como promotora da aprendizagem.

Outro possível aspecto negativo da repetência seria a contribuição para o inchaço das salas de aula ao dificultar a progressão entre as séries. A edição de 2012 do Pisa apontou que o Brasil comporta, em média, 36,91 estudantes por sala de aula, enquanto em países como Espanha, Estados Unidos e Portugal este 
número gira em torno de 25 estudantes por sala (BRASIL, 2014a). Não se sabe se a diminuição da repetência melhoraria diretamente o número de alunos por sala, até porque, se promovidos, muitos apenas ocupariam uma cadeira na série seguinte. Mas, certamente, ela não contribui para a constituição de salas mais enxutas quando alguns estudantes que poderiam estar formados e fora do sistema escolar continuam a permanecer neste.

Um fator importante é que, muitas vezes, promover ou repetir o estudante de ano não significa um custo extra naquele ano escolar, pois o repasse do Fundeb pode ser o mesmo para estudantes em séries subsequentes. Assim, esse custo só aparece ao final da escolarização, quando se revela que foram pagos 13 anos de estudo, ou mais, para um aluno obter o diploma de Ensino Médio, ao passo que seriam necessários apenas 12 anos.

Para Estados e municípios, o custo da repetência também fica mascarado, pois ter 26 ou 28 estudantes na mesma sala, praticamente não altera o seu custo principal de manutenção. Entretanto, ao se olhar os dados do Fundeb, pode verificar-se grande impacto financeiro em âmbito nacional. Mais além, a repetência poderia até ser financeiramente interessante, pois a unidade federativa recebe por um estudante que não acarreta muitas despesas adicionais, visto que a sala já funcionaria independentemente da inclusão de um ou outro estudante. Uma possibilidade para alterar essa lógica seria a remuneração por sala de aula com número máximo de estudantes, isso impediria o inchaço das salas e a remuneração individual por repetente.

A legislação que rege a distribuição de recursos deveria incorporar regras que contemplassem a questão da repetência. Por exemplo, evitando pagar duas vezes o mesmo ano escolar para o repetente ou um repasse reduzido do valor por aluno nesses casos. A redução dos valores pagos por estudantes repetentes permitiria a redistribuição dos recursos e o aumento do valor para os alunos regulares ou promovidos, constituindo um estímulo para promoção dos estudantes. O contraponto dessa medida seria a diminuição de recursos dos municípios ou Estados que têm os mais altos índices de repetência, ou seja, que atendem àqueles de menor nível socioeconômico.

É preciso ter clareza que simples medidas econômicas e produtivistas não irão resolver os problemas de aprendizagem dos estudantes. Sabe-se da existência de estudantes promovidos que apresentam dificuldades básicas em séries mais avançadas do Ensino Fundamental e Médio, e isso pode ser acentuado com a mera aprovação dos estudantes para se evitar perdas no repasse. Todavia, 
nas atuais regras do Fundeb, uma unidade federativa, ao reduzir a repetência, consequentemente pode também estar reduzindo o seu repasse do Fundeb; há um desestímulo para a redução da repetência.

Analogamente ao relatório do Pisa internacional, aqui se verificou serem altos os volumes financeiros associados à repetência escolar, residindo na casa dos bilhões de reais. Ao término, espera-se que esses custos possam receber maior atenção e serem mais bem canalizados para o aprimoramento da educação nacional. Sabe-se que a política de fundos educacionais, iniciada em 1996 e continuada com o atual Fundeb, constituíram importantes avanços no financiamento da educação, e este artigo busca apenas contribuir com novos elementos que ampliem a discussão sobre a distribuição dos insuficientes recursos educacionais. 


\section{Pisa and grade retention costs in Brazil}

\section{Abstract}

The Pisa 2012 report mentioned that Brazil has one of the highest rates of grade retention in the world, which is an expensive process. This study proposes a method for calculating the cost of retention using the Educational Census data to estimate the number of students who repeated a grade in 2012, and the cost per student presented in the National Fund for Basic Education (Fundeb). As showed by other studies, this cost is high, and there is a necessity to create new policies that take grade retention into consideration to distribute educational resources.

Keywords: Grade repetition. Fundeb. Pisa. School Census.

\section{Pisa y el costo de la repetición de curso en Brasil}

\section{Resumen}

Brasil está entre los países con mayor número de estudiantes repitentes de curso, conforme el reporte internacional de Pisa, que además muestra que esta circunstancia es muy costosa. Este estudio desarrolla una posibilidad de cálculo de costo de la repetición en Brasil, utilizando los datos del Censo Escolar de 2012 y 2013 para contabilizar los estudiantes repitentes, y los datos de costo por estudiante del Fondo Nacional para la Educación Básica (Fundeb). Como ha sido verificado en otros estudios, el costo de repetición es alto para el país, sugiriendo la creación de politicas que consideren los datos de repetición para la distribución de las inversiones financieras de la educación.

Palabras clave: Repetición. Fundeb. Pisa. Censo Escolar. 


\section{Referências}

ALVES, F.; ORTIGÃO, I.; FRANCO, C. Origem social e risco de repetência: interação raça-capital econômico. Cadernos de Pesquisa, São Paulo, v. 37, n. 130, p. 161-180, jan./abr. 2007. Disponível em: <http:// www.scielo.br/pdf/cp/v37n130/08.pdf > . Acesso em: 30 mar. 2014. DOI: $10.1590 / \mathrm{s} 0100-15742007000100008$

BRASIL. Ministério da Educação. Fundo Nacional do Desenvolvimento da Educação. Apresentação. Brasília, DF, 2014b. Disponível em: $<$ http:// www.fnde.gov.br/ financiamento/fundeb/fundeb-apresentacao $>$. Acesso em: 8 abr. 2014.

. Ministério da Educação. Fundo Nacional do Desenvolvimento da Educação. Distribuição do FUNDEB por Estado. Brasília, DF, 2012c. Disponível em: $<$ http://www.fnde.gov.br/arquivos/category/168-repasses-eexecucao-de-recursos?download=8029:repasse-de-recursos-distribuicao-dofundeb-por-estado-total-2012>. Acesso em: 8 abr. 2014.

. Ministério da Educação. Fundo Nacional do Desenvolvimento da Educação. Repasse consolidado (por UF, esfera de governo, origem e mês). Brasília, DF, 2014c. Disponível em: <http://www.fnde.gov.br/financiamento/ fundeb/fundeb-dados-estatisticos/item/972-repasse-de-recursos-do-fundeb? tmpl=component\&print=1>. Acesso em: 8 abr. 2014.

. Ministério da Educação. Instituto Nacional de Estudos e Pesquisas Educacionais Anísio Teixeira. Indicadores educacionais: taxas de rendimento 2012. Brasília, DF, 2012b.. Disponível em: <http://download. inep.gov.br/informacoes_estatisticas/indicadores_educacionais/2012/ taxas_rendimento/tx_rendimento_brasil_regioes_UFs_2012.zip $>$. Acesso em: 30 mar. 2014.

. Ministério da Educação. Instituto Nacional de Estudos e Pesquisas Educacionais Anísio Teixeira. Microdados do censo escolar de 2012. Brasília, DF, 2012a. Disponível em: <ftp://ftp.inep.gov.br/microdados/ micro_censo_ escolar_2012.zip>. Acesso em: 30 mar. 2014.

. Ministério da Educação. Instituto Nacional de Estudos e Pesquisas Educacionais Anísio Teixeira. Microdados do censo escolar de 2013. Brasília, DF, 2013b. Disponível em: <ftp://ftp.inep.gov.br/microdados/ micro_censo_ escolar_2013.zip>. Acesso em: 30 mar. 2014. 
BRASIL. Ministério da Educação. Instituto Nacional de Estudos e Pesquisas Educacionais Anísio Teixeira. Pisa 2012: questionário A do estudante. Brasília, DF, 2013a. Disponível em: <http://download.inep.gov. br/acoes_internacionais/pisa/itens/2013/questionario_a_estudante.pdf $>$. Acesso em: 30 mar. 2014.

. Ministério da Educação. Instituto Nacional de Estudos e Pesquisas Educacionais Anísio Teixeira. Relatório nacional Pisa 2012: resultados brasileiros. Brasília, DF, 2014a. Disponível em: <http://download.inep.gov. br/acoes_internacionais/pisa/resultados/2014/relatorio_nacional_PISA_2012 _resultados_brasileiros.pdf $>$. Acesso em: 30 mar. 2014 .

. Ministério da Educação. Portaria interministerial n ${ }^{0} 1.809$, de 28 de dezembro de 2011. Define e divulga os parâmetros anuais de operacionalização do Fundeb para o exercício de 2012. Diário Oficial da União, Brasília, DF, n. 250, 29 dez. 2011. Seção 1. Disponível em: <http:// www.fnde.gov.br/fnde/legislacao/portarias/item/3598-portaria-interministerialn\%C2\%B0-1809-de-28-de-dezembro-de-2011>. Acesso em: 08 abr. 2014.

EVASÃO e repetência custam R $\$ 4,8$ bilhões: dados do Inep mostram que a taxa de abandono escolar passa de $10 \%$, enquanto o percentual de alunos que perdem o ano chega a 12,5\%. O MEC promete mudanças no Ensino Médio. Correio Braziliense, Brasília, DF, 2 out. 2012. Disponível em: $<$ http://www.correiobraziliense.com.br/app/noticia/eu-estudante/ensino_ educacaobasica/2012/10/02/ensino_educacaobasica_interna,325407/evasao-erepetencia-custam-r-4-8-bilhoes.shtml>. Acesso em: 15 jul. 2014.

KLEIN, R. Uma re-análise dos resultados do PISA: problemas de comparabilidade. Ensaio: Avaliação e Políticas Públicas em Educação, Rio de Janeiro, v. 19, n. 73, p. 717-742, out/dez. 2011. DOI: $10.1590 / \mathrm{s} 0104-40362011000500002$

OCDE - Organisation for Economic Co-operation and Development. Pisa 2012rResults: what makes schools successful? Resources, polices and pratices. Paris: OECD Publishing, 2013. v. 4. DOI: 10.1787/9789264201156-em

REPETÊNCIA: um erro que se repete a cada ano. Nova Escola. Disponível em: $<$ http://revistaescola.abril.com.br/formacao/repetencia-erro-se-repetecada-ano-567983.shtml > Acesso em: 15 jul. 2014.

RIANI, J. L. R.; SILVA, V. C.; SOARES T. F. Repetir ou progredir? Uma análise da repetência nas escolas públicas de Minas Gerais. Educação e 
Pesquisa, São Paulo, v. 38, n. 3, p. 623-636, jul./set. 2012. Disponível em: $<$ http://educa.fcc.org.br/pdf/ep/v38n03/v38n03a06.pdf > . Acesso em: 30 mar. 2014. DOI: $10.1590 / \mathrm{s} 1517-97022012000300006$

RIBEIRO, S. C. A pedagogia da repetência. Estudos Avançados, São Paulo, v. 5, n. 12, 1991. Disponível em: <http://www.scielo.br/pdf/ea/v5n12/v5n12a02.pdf > Acesso em: 30 mar. 2014. DOI: 10.1590/s0103-40141991000200002

WEST, R. M. Is retaining students in the early grades self-defeating?

Disponível em: $<$ http://www.brookings.edu/research/papers/2012/08/16student-retention-west $>$. Acesso em: 15 jul. 2014.

\section{Informações do autor}

João Galvão Bacchetto: Psicólogo. Mestre em Educação, Universidade de São Paulo - USP. Participou do Programa Thomas J. Alexander Fellowship na Organização para a Cooperação e Desenvolvimento Econômico - OCDE. Contato: joao.bacchetto@inep.gov.br 